\title{
Estimating the rainfall erosivity factor from monthly precipitation data in the Madrid Region (Spain)
}

\author{
David Hernando*, Manuel G. Romana \\ Department of Civil Engineering - Transport, Technical University of Madrid, Profesor Aranguren 3, 28040 Madrid, Spain. \\ *Corresponding author. Tel.: +34 616585 256. Fax: +34 916633 354. E-mail: davhernando@gmail.com
}

\begin{abstract}
The need for continuous recording rain gauges makes it difficult to determine the rainfall erosivity factor $(R-$ factor) of the Universal Soil Loss Equation in regions without good spatial and temporal data coverage. In particular, the $R$-factor is only known at 16 rain gauge stations in the Madrid Region (Spain). The objectives of this study were to identify a readily available estimate of the $R$-factor for the Madrid Region and to evaluate the effect of rainfall record length on estimate precision and accuracy. Five estimators based on monthly precipitation were considered: total annual rainfall $(P)$, Fournier index $(F)$, modified Fournier index $(M F I)$, precipitation concentration index $(P C I)$ and a regression equation provided by the Spanish Nature Conservation Institute $\left(R_{I C O N A}\right)$. Regression results from 8 calibration stations showed that $M F I$ was the best estimator in terms of coefficient of determination and root mean squared error, closely followed by $P$. Analysis of the effect of record length indicated that little improvement was obtained for $M F I$ and $P$ over 5 year intervals. Finally, validation in 8 additional stations supported that the equation $R=1.05 \cdot M F I$ computed for a record length of 5 years provided a simple, precise and accurate estimate of the $R$-factor in the Madrid Region.
\end{abstract}

Keywords: Rainfall erosivity; $R$-factor; Universal Soil Loss Equation; Modified Fournier index; Soil erosion.

\section{INTRODUCTION}

Erosion models are a powerful tool for soil loss evaluation and land management. One of the most widely-used models is the Universal Soil Loss Equation (USLE) developed by Wischmeier and Smith $(1961,1965,1978)$. Compared to more complex physically-based erosion models, USLE is a simplistic empirical model. Despite the simplicity of USLE, determination of the rainfall erosivity factor ( $R$-factor) is no easy task. The $R$ factor for a single storm was defined by Wischmeier (1959) as the product of the total kinetic energy $(E)$ multiplied by the maximum 30-minute intensity $\left(I_{30}\right)$. The $R$-factor at a particular location is then obtained as the average of annual $E \cdot I_{30}$ values over long time intervals (over 20 years) to include apparent cyclical rainfall patterns (Wischmeier and Smith, 1978).

Although there are several equations for computing the kinetic energy of a storm (Brown and Foster, 1987; Wischmeier and Smith, 1978), all of them require continuous recording rain gauges with time resolution of at least 15 minutes. This need for continuous recording makes it difficult to determine the $R$ factor in many regions where good spatial and temporal data coverage is scarce. This is the case for the Madrid Region (Spain), where the $R$-factor has been only computed by the Spanish Nature Conservation Institute (ICONA) at 16 rain gauge stations based on rainfall data recorded from 1950 to 1985 (ICONA, 1988).

There have been many attempts worldwide to establish correlations between the $R$-factor calculated by the prescribed method and more readily available rainfall data, such as daily and monthly precipitation (Angulo-Martínez and Beguería, 2009; Bonilla and Vidal, 2011; Colotti, 2004; Diodato, 2004; Diodato and Bellochi, 2007; Lee and Heo, 2011; Loureiro and Coutinho, 2001; Petkovšek and Mikoš, 2004; Renard and Freimund, 1994; Salako, 2008; Yu and Rosewell, 1996; Yu et al., 2001). Nevertheless, most of the obtained equations have limited application out of the areas in which they were developed without a thorough validation analysis.
Therefore, the objectives of this study were: (1) to identify a readily available estimate of the rainfall erosivity factor for the Madrid Region, and (2) to evaluate the effect of rainfall record length on the precision and accuracy of the estimates.

\section{MATERIAL AND METHODS Rainfall erosivity estimators}

Based on the literature review conducted, five estimators of rainfall erosivity were selected for this study: total annual rainfall $(P)$, Fournier index $(F)$, modified Fournier index $(M F I)$, Oliver's precipitation concentration index $(P C I)$ and a regression model proposed by the Spanish Nature Conservation Institute $\left(R_{I C O N A}\right)$. Other factors such as Hudson's $K E>25$ index (Hudson, 1971), Lal's $A I_{m}$ index (Lal, 1976), Onchev's $P / S t$ universal index (Onchev, 1985), and Burst factor (Smithen and Schulze, 1982) were not considered since they still require continuous recording. A further description of selected estimators is provided below.

Fournier (1960) conducted a regression analysis between sedimentation in rivers and several rainfall variables, finding a high correlation between the total annual erosion and the distribution coefficient of rainfall or, most commonly named, Fournier index:

$$
F=\frac{p^{2}}{P}
$$

where $F$ is the Fournier index, $p$ is the precipitation in the wettest month and $P$ is the total annual rainfall.

Due to the simplicity in calculating the Fournier index, Arnoldus (1980) attempted to correlate this index with the known values of the rainfall erosivity factor for 164 rainfall stations in the United States and 14 stations in West Africa. The results were not satisfactory because of the different behavior of each index: while the $R$-factor adds all erosive storms, the Fournier index only captures those storms out of the month with 
the highest precipitation within the denominator (total annual rainfall). Thus, Arnoldus (1980) proposed a modification of the Fournier index in which the storms that occur outside the month of maximum rainfall increase the overall value of the index, obtaining significantly higher coefficients of determination $\left(r^{2}>0.80\right)$ :

$$
M F I=\sum_{i=1}^{12} \frac{p_{i}^{2}}{P}
$$

in which $M F I$ is the modified Fournier index, $p_{i}$ is the monthly rainfall and $P$ is the total annual rainfall. Colotti (2004) reported that the Food and Agriculture Organization (FAO) of the United Nations used the modified Fournier index as an erosion estimate according to the following general equation:

$$
R=a \cdot M F I+b
$$

where $R$ is the rainfall erosivity factor, MFI is the modified Fournier index, and $a$ and $b$ are two regional fitting parameters.

Ferro et al. (1991) stated that the $F_{F}$ index, which represents the average value of the modified Fournier index for an interval of $N$ years, is better correlated with the $R$-factor than both the mean annual precipitation and the modified Fournier index:

$$
F_{F}=\frac{1}{N} \sum_{j=1}^{N}\left[\sum_{i=1}^{12} \frac{p_{i, j}^{2}}{P_{j}}\right]=\frac{1}{N} \sum_{j=1}^{N} M F I_{j}
$$

where $p_{i, j}$ is the rainfall (mm) in month $i$ of year $j, P_{j}$ is the annual precipitation $(\mathrm{mm})$ of year $j$, and $N$ is the number of years considered. The $F_{F}$ index was also successfully used by Ferro et al. (1999) to estimate the $R$-factor in southern Italy and southeastern Australia.

Oliver (1980) proposed an index of rainfall concentration in order to estimate the aggressiveness of storms from the temporal variability of monthly precipitation:

$P C I=100 \frac{\sum_{i=1}^{12} p_{i}^{2}}{P^{2}}$

where $P C I$ is the precipitation concentration index, $p_{i}$ is the monthly rainfall and $P$ is the total annual rainfall.

In Spain, ICONA (1988) proposed the following regression equation to estimate the rainfall erosivity factor in the Madrid Region:

$$
R_{\text {ICONA }}=e^{-0,834} \cdot P M E X^{1,314} \cdot M R^{-0,388} \cdot F_{24}^{0,563}
$$

where $R_{I C O N A}$ is the rainfall erosivity factor $\left(\mathrm{MJ} \cdot \mathrm{cm} \cdot \mathrm{ha}^{-1} \cdot \mathrm{h}^{-1} \cdot \mathrm{year}^{-1}\right)$ as estimated by ICONA, PMEX is the maximum monthly precipitation (mm), $M R$ is the total rainfall from October to May (mm), and $F_{24}$ is the ratio of the square of the maximum annual rainfall in 24 hours $(\mathrm{mm})$ to the sum of the maximum monthly rainfall in 24 hours $(\mathrm{mm})$ :

$$
F_{24}=\frac{\left(P_{24 h, \text { annual }}\right)^{2}}{\sum_{i=1}^{12} P_{24 h, i}}
$$

Annual values for the period covered by each rainfall station were calculated for the five estimators. A series of values for each estimator were then obtained by averaging annual values over time intervals. These series were used to evaluate the effect of record length through regression analyses. The effect of record length on each estimator was studied using the following time intervals: 1, 2, 5, 10, 15 and 20 years, described by Eq. 8:

$X_{N}=\frac{1}{N} \sum_{i=1}^{N} X_{i}$

where $X_{N}$ represents the values of the estimator $\left(R_{I C O N A}, P, F\right.$, $M F I$ and $P C I$ ) for a record length of $N$ consecutive years, and $X_{i}$ is the annual value of the estimator in year $i$. Eq. 8 was applied to all consecutive $1,2,5,10,15$ and 20-year intervals within the period covered by each rainfall station.

\section{Study area}

The Madrid Region is located in central Spain (Figure 1), between the Atlantic Ocean and the Mediterranean Sea, in a high plateau around $600 \mathrm{~m}$ above sea level (a.s.l.). The study area lies between $39^{\circ} 53^{\prime} \mathrm{N}-41^{\circ} 10^{\prime} \mathrm{N}$ and $3^{\circ} 03^{\prime} \mathrm{W}-4^{\circ} 34^{\prime} \mathrm{W}$, covering a total extension of $8022 \mathrm{~km}^{2}$. The region is in the shape of a triangle (Figure 1), with the Central System mountain range on the NW side (elevations above $2400 \mathrm{~m}$ a.s.l.). From the base of the Central System, it begins a grade that ends in the Tagus valley (SE corner), with elevations below $500 \mathrm{~m}$ a.s.l. The area is dominated by a Mediterranean climate, characterized by seasonal temperatures, summer drought and erratic rainfall. The average annual rainfall of the area ranges from $1500 \mathrm{~mm}$ in the $\mathrm{NW}$ to $400 \mathrm{~mm}$ in the SE.

\section{Database}

The rain gauge network provided by the Spanish Meteorological Agency (AEMET) in the Madrid Region consists of more than 170 rainfall stations. However, ICONA (1988) only determined the $R$-factor according to the prescribed method at 16 stations. To date, no more attempts to determine the $R$-factor in additional stations have been published.

In this study, 8 stations were used for regression analysis (model calibration) between the single computed $R$-factor reported by ICONA (1988) and the five estimators presented previously $\left(R_{I C O N A}, P, F, M F I\right.$ and $\left.P C I\right)$. The equations obtained from these 8 calibration stations were then validated in 8 additional stations. Locations of the 16 stations are shown in Figure 1. Table 1 presents the station name, elevation, available $R$-factor, analysis period covered and number of complete years. For each station, monthly rainfall and maximum monthly rainfall in 24 hours were provided by AEMET.

\section{Statistical models}

Two statistical models were selected for this study. First, a simple linear regression with intercept term, as defined by equation 9:

$$
R=\beta_{0}+\beta_{1} \cdot X+\varepsilon
$$

where $R$ is the rainfall erosivity factor, $\beta_{0}$ is the intercept term, $\beta_{l}$ is the slope, $X$ is the estimator $\left(R_{I C O N A}, P, F, M F I\right.$ and $\left.P C I\right)$ and $\varepsilon$ represents the error.

It should be noted that the intercept term $\beta_{0}$ is just a fitting parameter which has no physical meaning since no erosion should occur for zero rainfall. Therefore, a simple linear 
regression through the origin (no intercept term) was defined as second statistical model:

$$
R=\beta_{2} \cdot X+\varepsilon
$$

in which $R$ is the rainfall erosivity factor, $\beta_{2}$ is the slope, $X$ is the estimator and $\varepsilon$ represents the error.
The assumptions for both models were that errors are independent of each other and normally distributed with a mean of zero and constant variance. Based on available rainfall data, a series of values for each estimator $\left(R_{I C O N A}, P, F, M F I\right.$ and $\left.P C I\right)$ and record length $(1,2,5,10,15$ and 20 years) were determined. These values were then correlated with the single computed $R$-factor reported by ICONA (1988) for each station.

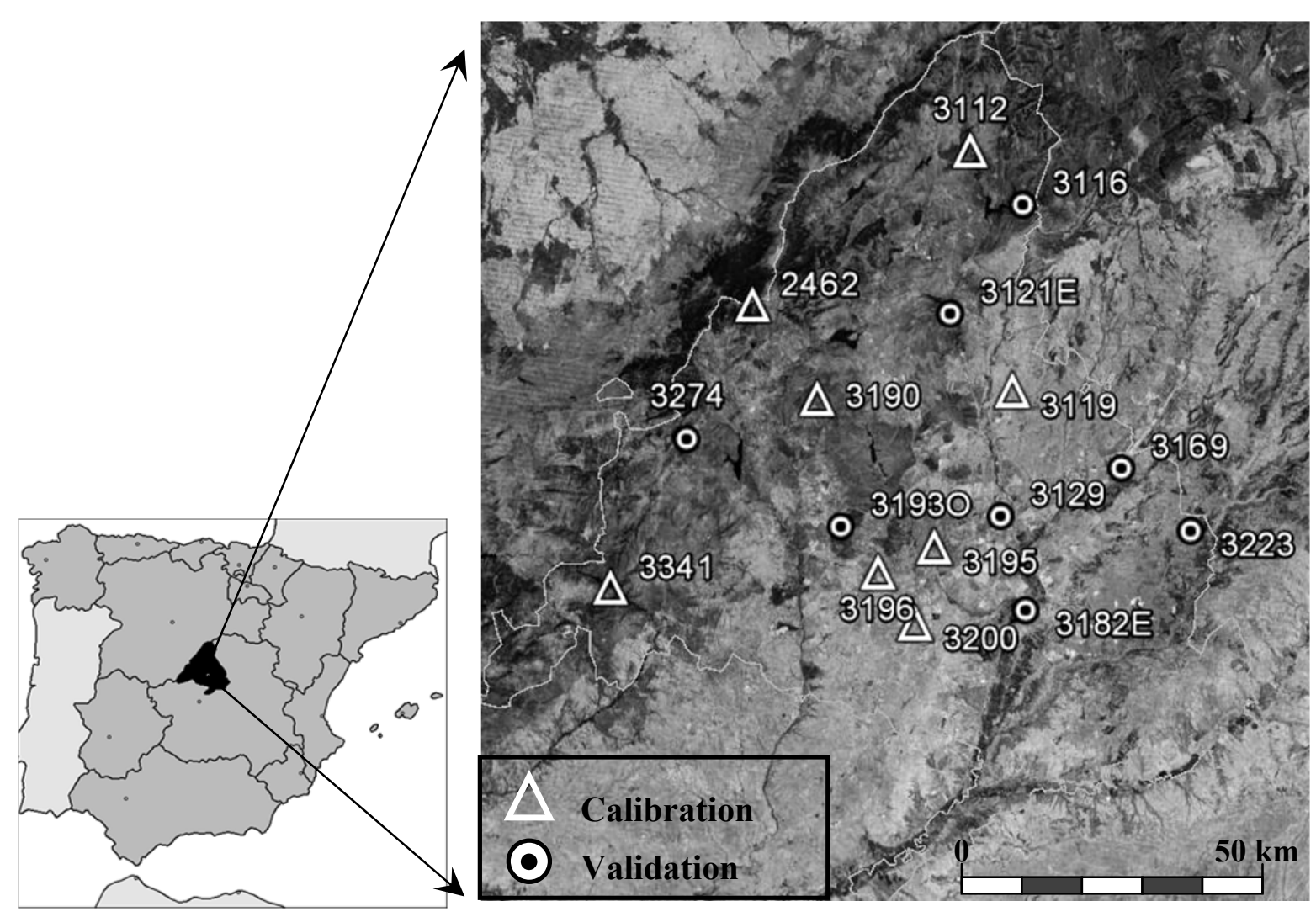

Fig. 1. Location of the study area and selected rainfall stations.

Table 1. Characteristics of rainfall stations selected for calibration and validation.

\begin{tabular}{|c|c|c|c|c|c|}
\hline Code & Station name & $\begin{array}{c}\text { Elevation } \\
\text { (m.a.s.1.) }\end{array}$ & $\begin{array}{c}R \text {-factor } \\
\left(\mathrm{MJ} \cdot \mathrm{cm}^{-1} \mathrm{ha}^{-1} \cdot \mathrm{h}^{-1} \cdot \mathrm{year}^{-1}\right) \\
(\mathrm{ICONA}, 1988)\end{array}$ & $\begin{array}{l}\text { Period } \\
\text { covered }\end{array}$ & $\begin{array}{c}\text { Complete } \\
\text { years }\end{array}$ \\
\hline \multicolumn{6}{|c|}{ Calibration } \\
\hline 2462 & Navacerrada & 1890 & 194 & $1947-2007$ & 61 \\
\hline 3112 & Puentes Viejas Dam & 960 & 89 & $1947-2004$ & 58 \\
\hline 3119 & Fuente El Saz & 645 & 63 & $1947-2007$ & 61 \\
\hline 3190 & Hoyo de Manzanares & 1100 & 124 & 1956-2007 & 52 \\
\hline 3195 & Madrid Retiro & 667 & 65 & $1947-2007$ & 61 \\
\hline 3196 & Madrid (Cuatro Vientos Airport) & 687 & 74 & $1947-2007$ & 61 \\
\hline 3200 & Getafe (Air Base) & 617 & 53 & 1951-2007 & 57 \\
\hline 3341 & San Juan Dam & 540 & 105 & $1952-1999$ & 47 \\
\hline \multicolumn{6}{|c|}{ Validation } \\
\hline 3116 & El Atazar Dam & 960 & 85 & 1970-2005 & 35 \\
\hline $3121 \mathrm{E}$ & El Vellón Dam & 850 & 87 & 1970-2007 & 38 \\
\hline 3129 & Madrid (Barajas Airport) & 582 & 65 & $1951-2007$ & 57 \\
\hline 3169 & Alcalá de Henares (Canaleja) & 600 & 62 & $1955-2004$ & 50 \\
\hline $3182 \mathrm{E}$ & Arganda & 530 & 66 & $1972-2007$ & 35 \\
\hline 31930 & Majadahonda (MAFRE) & 725 & 99 & 1976-2005 & 27 \\
\hline 3223 & Pezuela de las Torres & 852 & 69 & $1968-2007$ & 36 \\
\hline 3274 & San Lorenzo de El Escorial (Royal Seat) & 1028 & 130 & $1976-2005$ & 27 \\
\hline
\end{tabular}


Table 2. Regression results for $R$-factor $\left(\mathrm{MJ} \cdot \mathrm{cm} \cdot \mathrm{ha}^{-1} \cdot \mathrm{h}^{-1} \cdot \mathrm{year}^{-1}\right)$ in the 8 calibration stations.

\begin{tabular}{|c|c|c|c|c|}
\hline Estimator / Record length & Regression equation & $r^{2}$ & $\begin{array}{c}R M S E \\
\left(\mathrm{MJ} \cdot \mathrm{cm} \cdot \mathrm{ha}^{-1} \cdot \mathrm{h}^{-1} \cdot \text { year }^{-1}\right)\end{array}$ & $\begin{array}{c}\text { No. data } \\
\text { points }\end{array}$ \\
\hline \multicolumn{5}{|l|}{$R_{I C O N A}\left(\mathrm{MJ} \cdot \mathrm{cm} \cdot \mathrm{ha}^{-1} \cdot \mathrm{h}^{-1} \cdot \mathrm{year}^{-1}\right)$} \\
\hline 1 year & $R=0.30 \cdot R_{I C O N A}+64.13$ & 0.41 & 34 & 458 \\
\hline 2 years & $R=0.45 \cdot R_{I C O N A}+47.59$ & 0.63 & 27 & 226 \\
\hline 5 years & $R=0.81 \cdot R_{I C O N A}$ & 0.66 & 26 & 89 \\
\hline 10 years & $R=0.83 \cdot R_{I C O N A}$ & 0.80 & 20 & 43 \\
\hline 15 years & $R=0.84 \cdot R_{I C O N A}$ & 0.89 & 15 & 28 \\
\hline 20 years & $R=0.84 \cdot R_{I C O N A}$ & 0.91 & 14 & 20 \\
\hline \multicolumn{5}{|l|}{ Annual rainfall, $P(\mathrm{~mm})$} \\
\hline 1 year & $R=0.11 \cdot P+28.67$ & 0.70 & 24 & 458 \\
\hline 2 years & $R=0.12 \cdot P+20.08$ & 0.79 & 20 & 226 \\
\hline 5 years & $R=0.15 \cdot P$ & 0.87 & 16 & 89 \\
\hline 10 years & $R=0.15 \cdot P$ & 0.90 & 14 & 43 \\
\hline 15 years & $R=0.15 \cdot P$ & 0.91 & 13 & 28 \\
\hline 20 years & $R=0.15 \cdot P$ & 0.93 & 12 & 20 \\
\hline \multicolumn{5}{|l|}{ Fournier index, $F(\mathrm{~mm})$} \\
\hline 1 year & $R=0.82 \cdot F+63.83$ & 0.26 & 38 & 458 \\
\hline 2 years & $R=1.45 \cdot F+39.14$ & 0.46 & 33 & 226 \\
\hline 5 years & $R=2.42 \cdot F$ & 0.71 & 24 & 89 \\
\hline 10 years & $R=2.51 \cdot F$ & 0.87 & 16 & 43 \\
\hline 15 years & $R=2.51 \cdot F$ & 0.90 & 15 & 28 \\
\hline 20 years & $R=2.51 \cdot F$ & 0.92 & 13 & 20 \\
\hline \multicolumn{5}{|l|}{ Modified Fournier index, $M F I(\mathrm{~mm})$} \\
\hline 1 year & $R=0.73 \cdot M F I+29.51$ & 0.62 & 27 & 458 \\
\hline 2 years & $R=0.90 \cdot M F I+13.34$ & 0.78 & 21 & 226 \\
\hline 5 years & $R=1.05 \cdot M F I$ & 0.91 & 13 & 89 \\
\hline 10 years & $R=1.05 \cdot M F I$ & 0.94 & 11 & 43 \\
\hline 15 years & $R=1.05 \cdot M F I$ & 0.96 & 10 & 28 \\
\hline 20 years & $R=1.05 \cdot M F I$ & 0.96 & 9 & 20 \\
\hline
\end{tabular}

\section{RESULTS AND DISCUSSION \\ Regression analysis (model calibration)}

A preliminary analysis showed that regression results barely changed whether the period covered was that employed by ICONA (1950-1985) or a broader period. Thus, the decision was to consider the complete rainfall data set that was available for each rainfall station. Regression results obtained from the 8 calibration stations are presented in Table 2. These results include regression equation, coefficient of determination $\left(r^{2}\right)$ and root mean squared error (RMSE) for each estimator and record length. $P C I$ was found to be poorly correlated with $R$ factor so no results are presented hereafter. Assumptions of the statistical models were successfully validated. It was observed that the regression model through the origin $\left(\beta_{0}=0\right)$ provided $r^{2}$ and $R M S E$ values extremely close to those provided by the regression model with intercept term $\left(\beta_{0} \neq 0\right)$, especially for record lengths over 5 years. In fact, the intercept term was found not to be statistically significant in the regression analysis, so the simpler regression model without intercept term was proposed in Table 2 for record lengths of 5 years or more.

Overall, rather good results were provided by $R_{I C O N A}, P, F$ and $M F I$, especially for record lengths over 5 years. $M F I$ was the estimator with the best results in terms of $r^{2}$ and $R M S E$, closely followed by $P$. It should be pointed out that the equation obtained for the total annual rainfall $(R=0.15 \cdot P)$ closely agreed with previous results proposed by Van der Knijff et al. (2000) for Southern Europe $(R=0.13 \cdot P)$. Lastly, the slope of 0.84 obtained for $R_{I C O N A}$ when long record lengths were considered suggested that the available regression equation proposed by ICONA (Eq. 6) may overpredict the $R$-factor by approximately $16 \%$. A possible explanation is that Eq. 6 was developed for a broad area of Spain (not only the Madrid Region) and it may not perfectly fit the climatic pattern of the Madrid Region.

\section{Effect of record length on estimate precision and accuracy}

As can be inferred from Table 2, record length had a direct effect on regression models: as record length increased, $r^{2}$ increased and RMSE decreased. The reason is that as record length increased, the annual values of the estimators were averaged over a longer time interval as defined by Eq. 8. Thus, this 'smoothing' effect translated into less dispersion and, consequently, a better fitting.

In order to further analyze the effect of record length on the precision and accuracy of the estimates, two additional statistics were evaluated: the coefficient of variation $(\mathrm{CV})$ and the mean absolute percentage error (MAPE). $C V$ is defined as the ratio of the standard deviation to the mean of a sample, expressed as a percentage. This statistic represents the variability of an index 
about its mean value and represents the precision of the estimator. $M A P E$ is a measure of the error estimating the $R$-factor (accuracy) and is determined as follows:

$\operatorname{MAPE}(\%)=\frac{1}{N} \sum_{j=1}^{N}\left|\frac{R-\hat{R}_{j}}{R}\right|$

where $R$ is the known value of the rainfall erosivity factor (Table 1$), \hat{R}_{j}$ is the estimated value from the regression model, and $N$ is the number of data points for a given record length.

$C V$ results are presented in Figure 2. As can be seen in the figure, $P$ and $M F I$ were the estimators with the lowest $C V$ for any record length. $C V$ for $R_{I C O N A}$ and $F$ was almost twice that for $P$ and $M F I$. It can also be observed that $C V$ values barely changed for $P$ and $M F I$ over 5 years of record length whereas $R_{I C O N A}$ and $F$ required at least 10 years to become relatively constant.

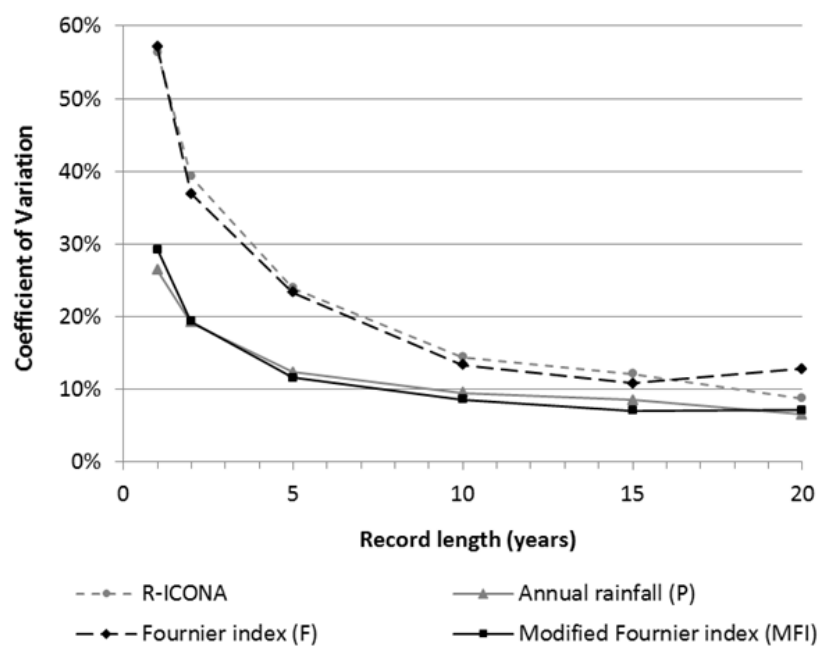

Fig. 2. Coefficient of variation for each estimator and record length (model calibration).

Figure 3 shows that $M F I$ was overall the estimator with the lowest $M A P E$. Again, small reductions in $M A P E$ were obtained for record lengths over 5 to 10 years. For $P$ and $M F I$ (the estimators with the lowest $M A P E$ values), $M A P E$ was below $13 \%$ for a record length as short as 5 years. In addition, a TukeyKramer honest significance difference (HSD) test revealed that $P$ and $M F I$ were statistically different from $R_{I C O N A}$ and $F$ for a $5 \%$ significance level when a 5 -year record length was considered.

The above results showed that record length definitely increased both the precision and accuracy of the estimates when

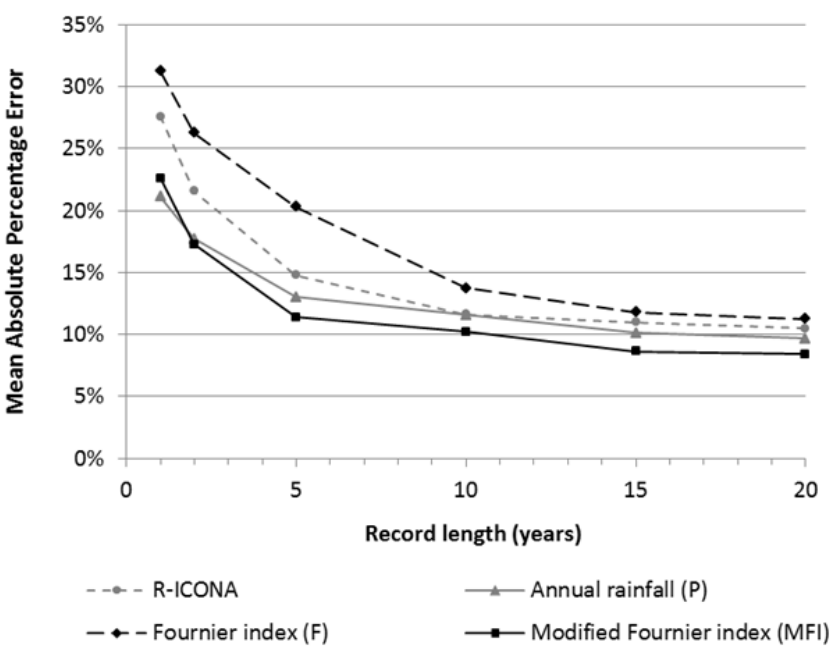

Fig. 3. Mean absolute percentage error for each estimator and record length (model calibration).

time intervals up to 10 years were considered, but there was almost no improvement beyond 10 years. In fact, both $P$ and $M F I$ provided quite good results (in terms of $C V$ and $M A P E$ ) for a record length of only 5 years. According to these results, a record length of 5 years could be considered adequate for $P$ and $M F I$, while a record length of 10 years could be proposed for $R_{\text {ICONA }}$ and $F$. Therefore, regression results in Table 2 were reduced to one single equation for each estimator, as shown in Table 3.

\section{Validation}

The simplified regression models obtained from the 8 calibration stations (Table 3) were used to estimate the $R$-factor in 8 additional stations. Results are shown in Figure 4, in which the y-axis represents measured $R$-factor reported by ICONA (Table 1) and the $\mathrm{x}$-axis represents predicted $R$-factor. As can be seen in the figure, the four estimators provided fairly good results for the proposed record lengths, observing only some dispersion for the station with the highest $R$-factor (San Lorenzo de El Escorial, $\left.R=130 \mathrm{MJ} \cdot \mathrm{cm} \cdot \mathrm{ha}^{-1} \cdot \mathrm{h}^{-1} \cdot \mathrm{year}^{-1}\right)$. RMSE and $M A P E$ were also evaluated for the validation stations. Figure 5 shows that RMSE values obtained from validation were rather close to those previously obtained from calibration, $P$ and $M F I$ being the estimators with the lowest RMSE. With respect to $M A P E$, Figure 6 indicates that validation results were similar to those observed from calibration, except for $R_{I C O N A}$, which experienced an important increase in estimate error due to the differences observed in one of the stations (San Lorenzo de El Escorial).

Table 3. Simplified regression models obtained from the 8 calibration stations.

\begin{tabular}{l|c|c|c|c|c|c}
\hline Estimator & Proposed record length & Regression equation & $r^{2}$ & $\begin{array}{c}R M S E \\
\left(\mathrm{MJ} \cdot \mathrm{cm}^{2} \cdot \mathrm{ha}^{-1} \cdot \mathrm{h}^{-1} \cdot \mathrm{year}^{-1}\right)\end{array}$ & $\begin{array}{c}C V \\
(\%)\end{array}$ & $\begin{array}{c}M A P E \\
(\%)\end{array}$ \\
\hline$R_{I C O N A}$ & 10 years & $R=0.83 \cdot R_{I C O N A, 10}$ & 0.80 & 20 & 14 & 12 \\
\hline$P$ & 5 years & $R=0.15 \cdot P_{5}$ & 0.87 & 16 & 12 & 13 \\
\hline$F$ & 10 years & $R=2.51 \cdot F_{10}$ & 0.87 & 16 & 13 & 14 \\
\hline$M F I$ & 5 years & $R=1.05 \cdot M F I_{5}$ & 0.91 & 13 & 12 & 11 \\
\hline
\end{tabular}



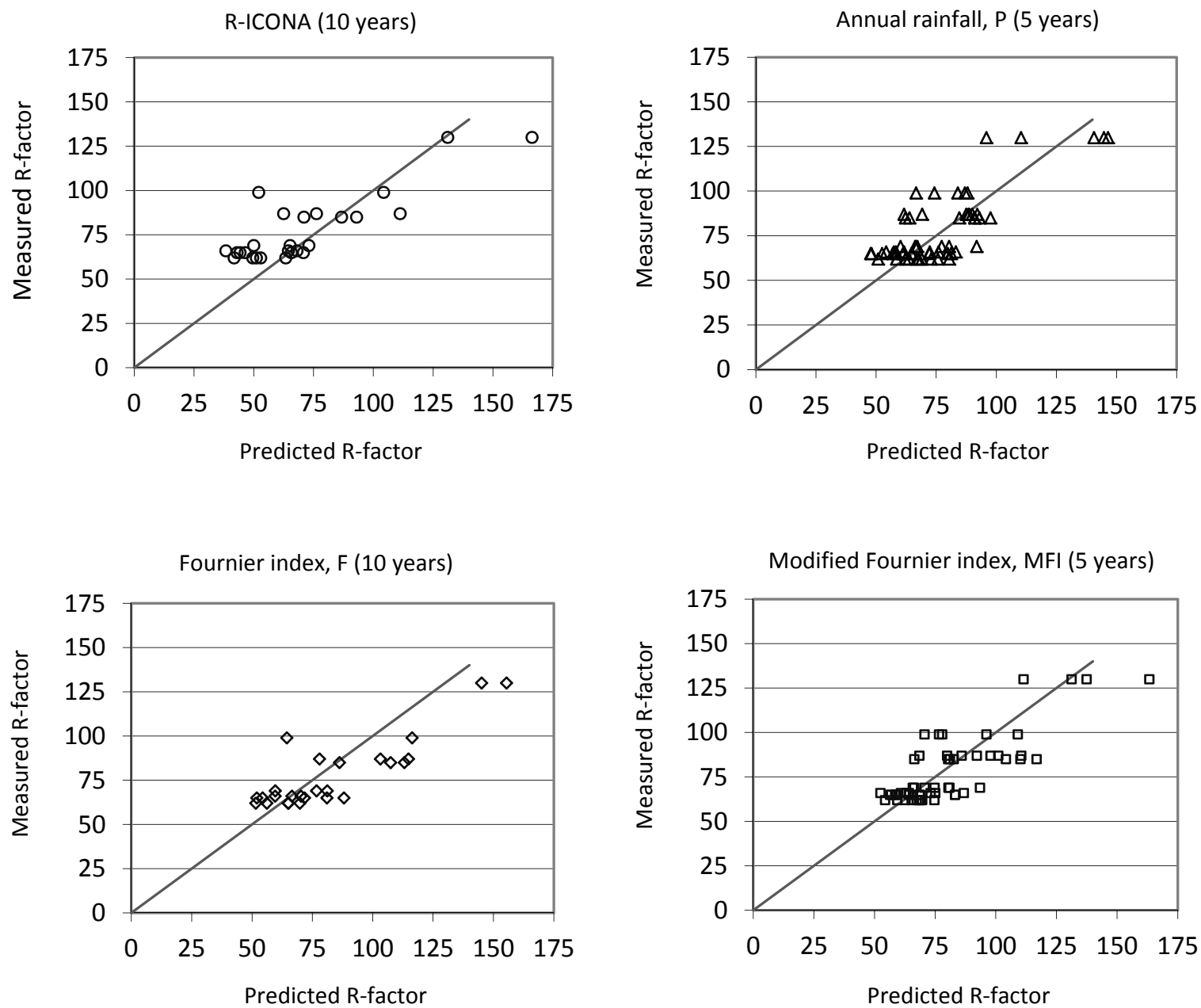

Fig. 4. Scatter plot of $R$-factor measured by ICONA vs. $R$-factor predicted by estimates for proposed record lengths in $\mathrm{MJ} \cdot \mathrm{cm}^{\prime} \cdot \mathrm{ha}^{-1} \cdot \mathrm{h}^{-1} \cdot \mathrm{year}^{-1}$ (model validation).

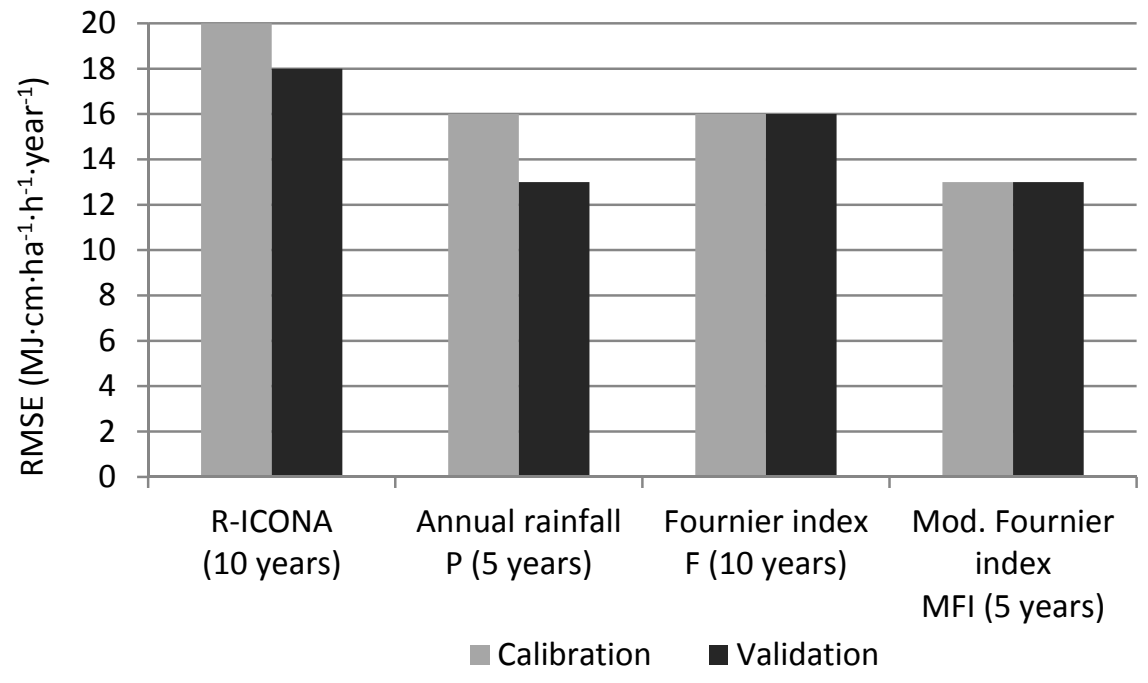

Fig. 5. Comparison of root mean squared error $(R M S E)$ results for calibration and validation. 


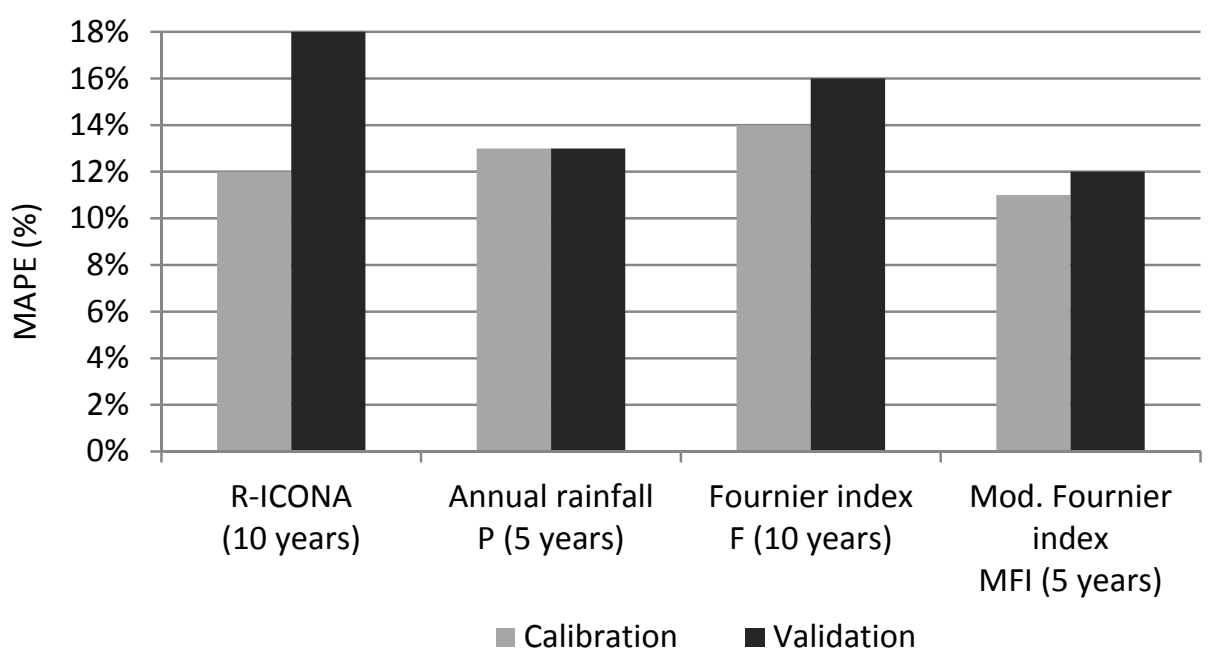

Fig. 6. Comparison of mean absolute percentage error $(M A P E)$ results for calibration and validation.

\section{CONCLUSIONS}

A detailed regression analysis of 16 rainfall stations throughout the Madrid Region resulted in the identification and validation of a readily available estimate of the rainfall erosivity factor. The findings and conclusions of this study can be summarized as follows:

- $\quad$ The modified Fournier index (MFI) provided the best estimates among the assessed indices for any record length, in terms of coefficient of determination $\left(r^{2}\right)$ and root mean squared error (RMSE) obtained from 8 calibration stations.

- Regression models through the origin resulted in $r^{2}$ and RMSE values extremely close to those obtained when intercept term was used, especially for record lengths of 5 years or more. In fact, the intercept term was found not to be statistically significant. Therefore, estimates with no intercept were selected for record lengths of 5 years or more.

- The analysis of the effect of record length on estimate precision and accuracy concluded that little improvement was obtained for $P$ and $M F I$ when time intervals over 5 years were considered. For $R_{I C O N A}$ and Fournier index, no improvement was observed over 10 years. Therefore, regression models were reduced to one single equation for each estimator.

- $\quad$ A Tukey-Kramer HSD test revealed that $P$ and $M F I$ were statistically different from $R_{I C O N A}$ and $F$ for a $5 \%$ significance level when a 5 -year record length was considered.

- Validation results from 8 additional stations confirmed that the equation $R=1.05 \cdot M F I_{5}$, in which $R$ is expressed in $\mathrm{MJ} \cdot \mathrm{cm} \cdot \mathrm{ha}^{-1} \cdot \mathrm{h}^{-1} \cdot$ year $^{-1}$ and $M F I_{5}$ represents the modified Fournier index obtained for a record length of 5 years (in $\mathrm{mm}$ ), provided a simple, precise and accurate estimate of the rainfall erosivity factor in the Madrid Region.

- $\quad$ The slope obtained for $R_{I C O N A}$ suggested that the regression equation previously proposed by ICONA (Eq. 6) may overpredict the $R$-factor in the Madrid Region by approximately $16 \%$.

Results from this study support that the rainfall erosivity factor can be successfully approximated at a local level (regional scale) by using readily available estimators based on monthly precipitation. Furthermore, the effect of record length can be assessed through the novel methodology described in this paper, which is based on the analysis of different statistics (namely coefficient of determination, root mean squared error, coefficient of variation and mean absolute percentage error) for different time intervals.

\section{REFERENCES}

Angulo-Martínez, M., Beguería, S., 2009. Estimating rainfall erosivity from daily precipitation records: a comparison among methods using data from the Ebro Basin (NE Spain). J. Hydrol., 379, 111-121.

Arnoldus, H.M.J., 1980. An approximation of the rainfall factor in the Universal Soil Loss Equation. In: De Boodt, M., Gabriels, D. (Eds.): Assessment of Erosion. John Wiley \& Sons, Chichister, pp. 127-132.

Bonilla, C.A., Vidal, K.L., 2011. Rainfall erosivity in Central Chile. J. Hydrol., 410, 1-2, 126-133.

Brown, L.C., Foster, G.R., 1987. Storm erosivity using idealized intensity distributions. Trans. ASAE, 30, 2, 379-386.

Colotti, E., 2004. Aplicabilidad de los datos de lluvia horaria en el cálculo de la erosidad. [Applicability of hourly rainfall data to erosion analysis]. Fondo Editorial de Humanidades y Educación. Departamento de Publicaciones. Universidad Central de Venezuela, Caracas. (In Spanish.)

Diodato, N., 2004. Estimating RUSLE's rainfall factor in the part of Italy with a Mediterranean rainfall regime. Hydrol. Earth Syst. Sci., 8, 1, 103-107.

Diodato, N., Bellochi, G., 2007. Estimating monthly (R)USLE climate input in a Mediterranean region using limited data. J. Hydrol., 345, 224-236.

Ferro, V., Giordano, G., Iovino, M., 1991. Isoerosivity and erosion risk map for Sicily. Hydrol. Sci. J., 36, 6, 549-564.

Ferro, V., Porto, P., Yu, B., 1999. A comparative study of rainfall erosivity estimation for southern Italy and southeastern Australia. J. Hydrol. Sci., 44, 1, 3-24.

Fournier, F., 1960. Climat et érosion. La relation entre l'érosion du sol par l'eau et les précipitations atmosphériques. [Relationship between soil erosion by water and rainfall]. Presses Universitaires de France, Paris. (In French.)

Hudson, N., 1971. Soil Conservation. Cornell University Press, Ithaca.

ICONA, 1988. Agresividad de la lluvia en España. Valores del factor $\mathrm{R}$ de la ecuación universal de pérdidas de suelo. [Rainfall erosivity in Spain. R-factor values for the Universal Soil Loss Equation]. Ministerio de Agricultura, Pesca y 
Alimentación, Madrid. (In Spanish.)

Lal, R., 1976. Soil erosion on alfisols in Western Nigeria IIIEffects of rainfall characteristics. Geoderma, 16, 389-401.

Lee, J.H., Heo, J.H., 2011. Evaluation of estimation methods for rainfall erosivity based on annual precipitation in Korea. J. Hydrol., 409, 1-2, 30-48.

Loureiro, N., Coutinho, M., 2001. A new procedure to estimate the RUSLE $\mathrm{EI}_{30}$ index, based on monthly rainfall data and applied to the Algarve region, Portugal. J. Hydrol., 250, 1-4, $12-18$.

Oliver, J.E., 1980. Monthly precipitation distribution: a comparative index. Professional Geographer, 32, 3, 300-309.

Onchev, N.G., 1985. Universal index for calculating rainfall erosivity. In: El-Swaify, S.A., Moldenhauer, W.C., Lo, A. (Eds.): Soil erosion and conservation. Soil Conservation Society of America, Ankeny, pp. 424-431.

Petkovšek, G., Mikoš, M., 2004. Estimating the R factor from daily rainfall data in the sub-Mediterranean climate of southwest Slovenia. Hydrol. Sci. J., 49, 5, 869-877.

Renard, K.G., Freimund, J.R., 1994. Using monthly precipitation data to estimate the R-factor in the revised USLE. J. Hydrol., 157, 287-306.

Salako, F.K., 2008. Rainfall variability and kinetic energy in Southern Nigeria. Climatic Change, 86, 151-164.

Smithen, A.A., Schulze, R.E., 1982. The spatial distribution in Southern Africa of rainfall erosivity for use in the Universal Soil Loss Equation. Water SA, 8, 2, 74-78.
Van der Knijff, J.M., Jones, R.J.A., Montanarella, L., 2000. Soil erosion risk. Assessment in Europe. Office for Official Publications of the European Communities, Luxemburg.

Wischmeier, W.H., 1959. A rainfall erosion index for a Universal Soil-Loss Equation. Soil Sci. Soc. Am. Proc., 23, 3, 246249.

Wischmeier, W.H., Smith, D.D., 1961. A universal equation for predicting rainfall-erosion losses - An aid to conservation farming in humid regions. ARS Special Report 22-66. U.S. Department of Agriculture, Washington, D.C.

Wischmeier, W.H., Smith, D.D., 1965. Predicting rainfall erosion losses from cropland East of the Rocky Mountains. Agriculture Handbook No. 282. U.S. Department of Agriculture, Washington, D.C.

Wischmeier, W.H., Smith, D.D., 1978. Predicting rainfall erosion losses. A guide to conservation planning. Agriculture Handbook No. 537. U.S. Department of Agriculture, Washington, D.C.

Yu, B., Rosewell, C.J., 1996. A robust estimator of the R factor for the Universal Soil Loss Equation. Trans. ASAE, 39, 559561.

Yu, B., Hashim, G.M., Eusof, Z., 2001. Estimating the R-factor with limited rainfall data: a case study from peninsular Malaysia. J. Soil Water Conserv. 56, 2, 101-105.

Received 5 March 2014 Accepted 21 August 2014 